\title{
A systematic review of Terson's syndrome: frequency and prognosis after subarachnoid haemorrhage
}

\author{
M O McCarron, M J Alberts, P McCarron
}

J Neurol Neurosurg Psychiatry 2004;75:491-493. doi: 10.1136/jnnp.2003.016816

\begin{abstract}
Objective: To review systematically the frequency and prognostic significance of vitreous haemorrhage in patients with subarachnoid haemorrhage (Terson's syndrome).

Methods: Papers relating to vitreous haemorrhage in patients with subarachnoid haemorrhage were retrieved. The only studies considered were those with at least 10 consecutive cases of subarachnoid haemorrhage with or without vitreous haemorrhage. The frequency of vitreous haemorrhage in such cases was calculated in prospective and retrospective studies. Mortality was compared in patients with and without Terson's syndrome.

Results: 154 papers were reviewed. Three prospective studies and six retrospective studies satisfied the inclusion criteria. Of 181 patients with subarachnoid haemorrhage assessed prospectively (mean age, 51.7 years), 24 (13\%) had vitreous haemorrhage; among 1086 retrospective records, 37 (3\%) had documented vitreous haemorrhage $(p<0.001)$. Patients with Terson's syndrome had higher Hunt and Hess grades than those without (mean grade, $3.6 v 2.6$ ). Patients with Terson's syndrome were also more likely to die (13 of $30(43 \%) v 31$ of $342(9 \%)$; odds ratio $4.8 ; p<0.001$ ). Conclusions: Prospective studies show a higher frequency of Terson's syndrome than retrospective studies, suggesting that vitreous haemorrhage is not well documented. Vitreous haemorrhage is an adverse prognostic finding in patients with subarachnoid haemorrhage.
\end{abstract}

$\mathrm{V}$ itreous haemorrhage occurring in association with subarachnoid haemorrhage is known as Terson's syndrome. The French ophthalmologist, Albert Terson, is credited with discovering this clinical sign in a patient with subarachnoid haemorrhage in 1900, ${ }^{1}$ although in 1881 Litten described vitreous bleeding occurring in association with subarachnoid haemorrhage. ${ }^{2}$ In general, published reports on Terson's syndrome have failed to make the distinction between vitreous haemorrhage and other types of intraocular haemorrhage (retinal and subhyaloid haemorrhages). ${ }^{3}$ As a result, information and natural history data using the strict definition of Terson's syndrome have been limited. However, intraocular haemorrhages of any type (retinal, subhyaloid, or vitreous) have been documented in $10-40 \%$ of individuals with subarachnoid haemorrhage. ${ }^{4}$

In the early part of the 20th century clinicians speculated that the size and number of retinal haemorrhages may have clinical relevance. ${ }^{5}$ Manschot suggested that "intracranial haemorrhage is more pronounced in patients with bilateral retinal haemorrhages than in patients with haemorrhages in only one eye. ${ }^{16}$ Furthermore it was suggested that any type of intraocular haemorrhage in patients with subarachnoid haemorrhage may also be associated with increased mortality. ${ }^{7}$
Until relatively recently vitreous haemorrhage was thought to be a rare finding in patients with subarachnoid haemorrhage, ${ }^{89}$ but small prospective studies have questioned this view. ${ }^{10}{ }^{11}$ Our aim in this study was to obtain, from published reports, a summary estimate of the frequency of vitreous haemorrhage in patients with subarachnoid haemorrhage, and to compare the baseline characteristics and mortality in patients with and without vitreous haemorrhage.

\section{METHODS}

Published articles relating to vitreous haemorrhage in patients with subarachnoid haemorrhage were retrieved using the key words "subarachnoid haemorrhage," "vitreous haemorrhage," and "Terson syndrome" on Medline (Ovid and PubMed) and Embase databases from 1966 until May 2003. Publications predating 1966, and others missed by the search, were sought by scanning the bibliographies of retrieved articles, and by surveillance of paper and electronic journals.

Inclusion criteria required studies with enrolment of at least 10 consecutive unselected patients of any age with subarachnoid haemorrhage, with or without vitreous haemorrhage. Studies which did not explicitly document the prospective nature of the study were classified as retrospective. Vitreous haemorrhage was considered present only when there was clear documentation of this type of haemorrhage. Patients with delayed vitreous haemorrhage were included in the Terson's syndrome group. Other forms of intraocular haemorrhage (retinal and subhyaloid) were excluded from the analyses.

In all, 154 papers were retrieved, and from these, nine studies fulfilled the inclusion criteria. ${ }^{4} 7^{10-16}$

\section{Statistical analysis}

The frequency of vitreous haemorrhage in patients with subarachnoid haemorrhage was calculated in prospective and retrospective studies. The association between risk of death in patients with subarachnoid haemorrhage with and without vitreous haemorrhage was investigated by calculating odds ratios and doing $\chi^{2}$ tests with the Yates correction.

\section{RESULTS}

\section{Frequency of Terson's syndrome}

Three prospective studies satisfied the inclusion criteria. ${ }^{10}{ }^{11} 14$ All three were reported in the 1990s. Two reports appeared to be from the same cohort of patients. ${ }^{11}{ }^{13}$ The mean age of the 181 patients reported in the prospective studies was 51.7 years. There were more than twice as many women as men, a finding consistent with the sex difference in the incidence of aneurysmal subarachnoid haemorrhage. Only one of the patients with Terson's syndrome had a traumatic haemorrhage. ${ }^{10}$

Twenty four (13\%) of the 181 patients had evidence of vitreous haemorrhage (table 1). Bilateral vitreous haemorrhages were recorded in nine of 16 patients with Terson's 


\begin{tabular}{|c|c|c|c|c|c|}
\hline Report & $\begin{array}{l}\text { No of patients } \\
\text { with } S A H(M / F)\end{array}$ & $\begin{array}{l}\text { Mean age } \\
\text { (years) }\end{array}$ & $\begin{array}{l}\text { No of patients } \\
\text { with Terson's } \\
\text { syndrome (\%) }\end{array}$ & $\begin{array}{l}\text { Reported deaths } \\
\text { in Terson's } \\
\text { syndrome (\%) }\end{array}$ & $\begin{array}{l}\text { Reported deaths in } \\
\text { SAH without Terson's } \\
\text { syndrome (\%) }\end{array}$ \\
\hline \multicolumn{6}{|l|}{ Prospective } \\
\hline Garfinkle & $22(6 / 16)$ & 55 & $6(27)$ & 2 of 6 & 5 of 16 \\
\hline Pfausler $^{14}$ & $60(23 / 37)$ & 50 & $10(17)$ & 9 of 10 & 5 of 50 \\
\hline Frizzell" & $99(27 / 72)$ & 52 & $8(8)$ & 1 of 8 & 7 of 91 \\
\hline Prospective total & $181(56 / 125)$ & 52 & $24(13)$ & 12 of $24(50)$ & 17 of 157 (11) \\
\hline \multicolumn{6}{|l|}{ Retrospective } \\
\hline Timberlake $^{12}$ & 280 & - & $12(4)$ & - & - \\
\hline Krawczykowa ${ }^{15}$ & 100 & - & $3(3)$ & - & - \\
\hline Fahmy $^{4}$ & $195(95 / 100)$ & - & $9(5)$ & - & - \\
\hline Shaw ${ }^{7}$ & 320 & - & 7 (2) & - & - \\
\hline Diaz $^{16}$ & 19 & - & $2(11)$ & 0 of 2 & 5 of 17 \\
\hline Shinoda ${ }^{17}$ & $172(81 / 91)$ & - & 4 (2) & 1 of 4 & 9 of 168 \\
\hline Retrospective total & 1086 & - & $37(3)$ & 1 of 6 (17) & 14 of 185 (8) \\
\hline Total & 1267 & & $61(5)$ & 13 of $30(43)$ & 31 of 342 (9) \\
\hline
\end{tabular}

syndrome (56\%) who had explicit documentation of involvement of one or both eyes. In the two prospective studies which reported the sex of the participants, ${ }^{10}{ }^{14}$ there was no evidence of a difference in the sex ratio between those with vitreous haemorrhage and those without. The age of the patients with and without Terson's syndrome was similar in the two studies in which mean age was available ${ }^{10}{ }^{11}$ : mean age 55.2 years (range 36 to 74 ) in 14 patients with Terson's syndrome, versus 52 years (range 16 to 85) in 107 patients without vitreous haemorrhages. Although most aneurysms in the patients with Terson's syndrome were located in the anterior circulation (13 of 14), there were insufficient data for comparative analyses.

Six retrospective studies were identified (table 1). These provided fewer details of age and sex, and less information about the existence of bilateral vitreous haemorrhages. The incidence of Terson's syndrome was much lower among these studies than among the prospective studies (3\% $v 13 \%$, $\mathrm{p}<0.001$ ).

\section{Outcome}

Only prospective studies recorded the patients' clinical condition in the form of mean Hunt and Hess grades, which were consistently higher in patients with Terson's syndrome than in those without (fig 1). Insufficient information was provided in the studies to estimate summary case fatality rates. Deaths were recorded in just five studies (three prospective and two retrospec-

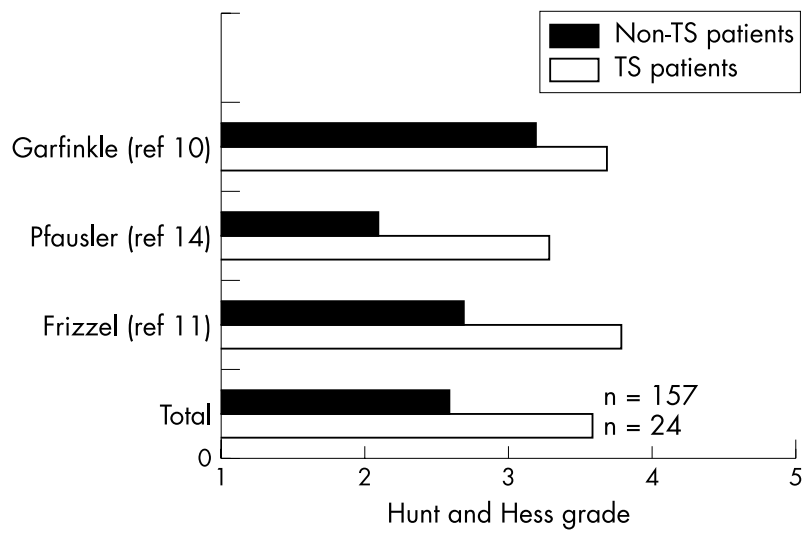

Figure 1 Mean Hunt and Hess grades in patients with and without Terson's syndrome (TS). tive). ${ }^{1011141617}$ From these limited data, death was more common in patients with Terson's syndrome (especially in the prospective studies) than in those without: 13 of 30 patients with Terson's syndrome (43\%) died, compared with 31 of $342(9 \%)$ without Terson's syndrome, giving a 4.8 -fold excess risk of death in patients with Terson's syndrome $(\mathrm{p}<0.001)$.

\section{DISCUSSION}

\section{Terson's syndrome frequency and mortality}

This systematic review of reports of Terson's syndrome dating back more than 100 years shows that the combination of subarachnoid haemorrhage and vitreous haemorrhage occurred in $13 \%$ of hospital admissions with subarachnoid haemorrhage who survived long enough to allow clinical assessment. Our review shows clearly that prospective studies identify many more patients with vitreous haemorrhage than retrospective studies. Previous investigators suspected the importance of this methodological issue. ${ }^{7}$

The mortality analyses that we were able to carry out in the current study confirm previous suggestions that Terson's syndrome is associated with a worse outcome than in patients with subarachnoid haemorrhage but without vitreous haemorrhage.

Some of the previous studies did not distinguish vitreous haemorrhage from other types of intraocular haemorrhage. ${ }^{6}$ However, the current findings suggest that vitreous haemorrhage on its own is an indicator of poor prognosis in patients with subarachnoid haemorrhage. In one study ${ }^{18}$ there was also a suggestion that different types of intraocular haemorrhage had different prognostic significance, in that mild retinal haemorrhages were associated with a better prognosis than large preretinal haemorrhages or vitreous haemorrhages. ${ }^{18}$

Although it has been less studied as an individual clinical feature, preretinal haemorrhage is thought often to precede vitreous haemorrhage. ${ }^{4} 7$ The greater proportion of patients developing Terson's syndrome in the prospective studies may partly have resulted from delay in the appearance of vitreous haemorrhage, though even in the prospective studies serial clinical eye examinations were seldom reported. ${ }^{11}$ Studies have estimated that $12-16 \%$ of patients with subarachnoid haemorrhage do not reach hospital to be clinically assessed ${ }^{19} 20$; many such patients may have had vitreous haemorrhage or they may have died before vitreous haemorrhages developed. ${ }^{14}$ Thus any summary 
estimate may not reflect the true prevalence of this clinical feature, so the prognostic significance may also be inaccurate.

\section{Other clinical correlations of vitreous haemorrhage} Fahmy has pointed out that any retinal haemorrhage in a patient who has temporarily lost consciousness is very suggestive of aneurysmal rupture, occurring in about one third of cases of subarachnoid haemorrhage. ${ }^{21}$ Aneurysms the internal carotid artery and anterior communicating artery resulted in the most severe haemorrhage, ${ }^{21}$ but this finding has not been confirmed. Where documented, there also appeared to be no correlation between the side of a unilateral vitreous haemorrhage and the side or site of the aneurysm. $^{1421}$

\section{Pathogenesis of vitreous haemorrhage}

The pathogenesis of vitreous haemorrhage has been much debated. $^{5922}$ Increased intracranial pressure may force blood into the subarachnoid space and along the optic nerve sheath into the pre-retinal space, or the sudden rise in intracranial pressure may lead to a decrease in venous return to the cavernous sinus or obstruct the retinochoroidal anastomoses and central retinal vein, culminating in venous stasis and haemorrhage. It is now generally accepted that vitreous haemorrhage results from ocular blood. ${ }^{922} 23$

\section{Strengths and limitations}

As Terson's syndrome has been recognised for more than 100 years, any systematic review risks missing important studies not covered by computer searches. Identification of papers published before 1966 relied heavily on bibliographic searching. It had been thought that by 1962 only 16 cases of Terson's syndrome had been reported. ${ }^{8}{ }^{9}$ However, our search identified 21 patients with vitreous haemorrhage co-existing with subarachnoid haemorrhage reported before 1963. ${ }^{125812222425}$ On the other hand, the arrival of cerebral angiography followed by computed tomography in the 1970s yielded many more patients who had demonstrable subarachnoid haemorrhage in the presence of vitreous haemorrhage.

Population based prospective studies with pathological confirmation are required so that more complete accurate data can be collected. Our review of Terson's syndrome is restricted to hospital based studies of patients with subarachnoid haemorrhage. Even access to retrospective necropsy material is limited, as eyes are seldom examined at necropsy. ${ }^{22}$ Accurate case fatality rates could not be determined in the patients with Terson's syndrome as only one of the prospective studies ${ }^{14}$ provided sufficient mortality data. Thus documentation of vitreous haemorrhage is required in all patients with subarachnoid haemorrhage, especially as most deaths are a direct result of the neurological consequences of subarachnoid bleeding. ${ }^{20}$

\section{Conclusions}

This systematic review shows that vitreous haemorrhage, including bilateral haemorrhages, is a relatively common finding in patients with subarachnoid haemorrhage and can be identified by careful serial clinical examination. Univariate analyses suggest that vitreous haemorrhage is an indicator of poor prognosis in subarachnoid haemorrhage. For an accurate assessment of the incidence of Terson's syndrome, and whether vitreous haemorrhage is an independent prognostic variable in patients with subarachnoid haemorrhage, larger, more detailed, and ideally population based prospective studies are required.

\section{Authors' affiliations}

M O McCarron, Department of Neurology, Royal Victoria Hospital, Belfast, UK

M J Alberts, Department of Neurology, Northwestern University Medical School, Chicago, Illinois, USA

P McCarron, Department of Epidemiology and Public Health Medicine, Queen's University of Belfast

Competing interests: none declared

Correspondence to: Dr Mark McCarron, Department of Neurology, Altnagelvin Hospital, Londonderry BT47 6SB, UK;

markmccarron@doctors.org.uk

Received 4 May 2003

In revised form 28 July 2003

Accepted 5 August 2003

\section{REFERENCES}

1 Terson A. De l'hémorrhagie dans le corps vitre au cours de l'hémorrhagie cerebrale. Clin Ophthalmol 1900;6:309-12.

2 Litten M. Ueber Einige vom Allgemein-Klinischen Standpunkt aus Interessante Augenveränderungen. Berl Klin Wochenschr 1881;18:23-7.

3 Manschot WA. Subarachnoid hemorrhage: intraocular symptoms and their pathogenesis. Am J Ophthalmol 1954;38:501-5.

4 Fahmy JA. Fundal haemorrhages in ruptured intracranial aneurysms. I. Material, frequency and morphology. Acta Ophthalmol 1973;51:289-98.

5 Riddoch G, Goulden C. On the relationship between subarachnoid and intraocular haemorrhage. Br J Ophthalmol 1925;9:209-33.

6 Manschot WA. The fundus oculi in subarachnoid haemorrhage. Acta Ophthalmol 1944;22:281-99.

7 Shaw HEJ, Landers MB, Sydnor CF. The significance of intraocular hemorrhages due to subarachnoid hemorrhage. Ann Ophthalmol 1977;9:1403-5.

8 Paunoff F. Glaskörperblutungen bei Subarachnoidalblutung (Terson syndrom) Bericht über den 16.Fall der Weltliteratur [abstract]. Klin Mbl Augenheilk 1962;141:625

9 Castren JA. Pathogenesis and treatment of Terson syndrome. Acta Ophthalmol 1963;41:430-4

10 Garfinkle AM, Danys IR, Nicolle DA, et al. Terson's syndrome: a reversible cause of blindness following subarachnoid hemorrhage. J Neurosurg 1992;76:766-71

11 Frizzell RT, Kuhn F, Morris R, et al. Screening for ocular hemorrhages in patients with ruptured cerebral aneurysms: a prospective study of 99 patients. Neurosurgery 1997:41:529-33.

12 Timberlake WH, Kubik CS. Follow-up report with clinical and anatomical notes on 280 patients with subarachnoid hemorrhage. Trans Am Neurol Assoc 1952;77:26-30.

13 Kuhn F, Morris R, Witherspoon CD, et al. Terson syndrome. Results of vitrectomy and the significance of vitreous hemorrhage in patients with subarachnoid hemorrhage. Ophthalmology 1998;105:472-7.

14 Pfausler B, Beld R, Metzler R, et al. Terson's syndrome in spontaneous subarachnoid hemorrhage: a prospective study in 60 consecutive patients. J Neurosurg 1996;85:392-4.

15 Krawczykowa Z, Mert B, Skwierczynska J. Retinal and vitreal haemorrhages in the course of subarachnoid haemorrhage. Klin Oczna 1971;41:649-53.

16 Diaz AG, Carmena JJ, Martin R, et al. Intraocular hemorrhage in sudden increased intracranial pressure (Terson syndrome). Ophthalmologica 1979;179:173-6.

17 Shinoda J, Iwamura M, Iwai T, et al. Intraocular haemorrhage in ruptured intracranial aneurysm. Clinical study of 172 cases and reference to Terson's syndrome. Neurol Med Chir 1983;23:349-54. [In Japanese.]

18 Fahmy JA. Fundal haemorrhages in ruptured intracranial aneurysms. II. Correlation with the clinical course. Acta Ophthalmol 1973;51:299-304.

19 Pobereskin LH. Incidence and outcome of subarachnoid haemorrhage: a retrospective population based study. J Neurol Neurosurg Psychiatry $2001 ; 70: 340-3$

20 Bamford J, Dennis $M$, Sandercock $P$, et al. The frequency, causes and timing of death within 30 days of a first stroke: the Oxfordshire Community Stroke Project. J Neurol Neurosurg Psychiatry 1990;53:824-9.

21 Fahmy JA. Symptoms and signs of intracranial aneurysms with particular reference to retinal haemorrhage. Acta Ophthalmol 1972;50:129-36.

22 Ballantyne AJ. The ocular manifestations of spontaneous subarachnoid haemorrhage. Br J Ophthalmol 1943;27:383-414.

23 Ogawa T, Kitaoaka T, Dake Y, et al. Terson syndrome: a case report suggesting the mechanism of vitreous hemorrhage. Ophthalmology $2001 ; 108: 1654-6$.

24 Terson A. Le syndrome de l'hématome du corps vitré et de l'hémorragie intracranienne spontanés. Ann Oculistique 1926;163:666-73.

25 Doubler FH, Marlow SB. A case of hemorrhage into the optic nerve sheath as a direct extension from a diffuse intra-meningeal hemorrhage caused by rupture of aneurysm of a cerebral artery. Arch Ophthalmol 1917;46:533-6. 